\title{
Effect of Blue Colour (453 nm Visible Range Radiation) on Anxiety in College Students
}

\author{
Samina Azeemi' ${ }^{1}$, Hina Iram¹, Qanita Younas' ${ }^{1}$ Ameena Azeemi² \\ ${ }^{1}$ Department of Physics, Government College (W) Gulberg, Lahore, Pakistan \\ ${ }^{2} \mathrm{CMH}$ Lahore Medical College, Lahore, Pakistan \\ Email: saminatazayyen@yahoo.com
}

How to cite this paper: Azeemi, S., Iram, H., Younas, Q. and Azeemi, A. (2018) Effect of Blue Colour (453 nm Visible Range Radiation) on Anxiety in College Students. Chinese Medicine, 9, 1-6. https://doi.org/10.4236/cm.2018.91001

Received: January 3, 2018

Accepted: March 3, 2018

Published: March 6, 2018

Copyright (c) 2018 by authors and Scientific Research Publishing Inc. This work is licensed under the Creative Commons Attribution International License (CC BY 4.0).

http://creativecommons.org/licenses/by/4.0/

(c) (i) Open Access

\begin{abstract}
The Biological effect of blue color therapy on self-reported anxiety in college students was determined. Female students $(n=150)$ of age $18-24$ from a Government college ( $w$ ) Gulberg in Lahore, Pakistan were randomized into two groups ( $\mathrm{n}=75$ each), Group A (chromotherapy) and Group B (control). For the treatment of anxiety, two methods of chromo therapy used were Hydrochromotherapy (Blue chromotized water) and through watching colors (Blue chart). After 2, 4 and 6 weeks, the number of students experiencing improvement in their anxiety from Group A were 60, 9 and 0 respectively. In Group B, students that recovered from anxiety were 17, 12 and 7 after 2, 4 and 6 weeks respectively. Relation between therapy and improvement in anxiety was examined using $\chi^{2}$ statistic. Relation between these variables was significant, $(1, \mathrm{n}=150)=11.24, p<0.01$. After this study, $453 \mathrm{~nm}$ (blue color) was proved to be an effective intervention for anxiety in students. It confers a greater improvement in anxiety than does no treatment (control). This is cost effective yet an effective way of treatment with no apparent side effects.
\end{abstract}

\section{Keywords}

Color Therapy, Electromagnetic Radiation, Randomized Controlled Trial, Anxiety, Students

\section{Introduction}

University and college counseling centers, during the last few years, have described a change in the needs of students looking for counseling services, from more informational needs, to more serious psychological issues [1]. The researchers e.g. Offer and Spiro [2] concluded that more than $30 \%$ of the university students had a psychological problem and $25 \%$ of students seeking admission 
in college were disturbed and required psychological healthcare services. Psychological problems impacting college and university students have short and long-term consequences including decreased work capacity and declined academic performance [3].

Chromotherapy, an emerging technique, uses the visible spectrum (colors) of electromagnetic radiations to cure ailments [4]. In the past few years, Colour Therapy has emerged as a therapeutic option for the treatment of various psychological problems and Psychiatric Illnesses [5] [6]. It has been also regarded as an effective intervention in Insomnia [7], and has been known to affect Circadian Rhythms [8].

There is a lack of effective therapeutics for treating mild to moderate anxiety experienced by a large proportion of college students. If the effectiveness of chromotherapy in psychological problems experienced by the students could be justified, then this could provide an alternative treatment, alongside psychological interventions.

The primary aim of the study was to determine whether Colour therapy treatment produces a greater improvement on self-reported anxiety than does usual supportive care. Chromotherapy was adopted for this study because it has been reported with no side effects by the doctrine of chromotherapy [9].

The results of the present study might prove helpful and of importance to both health professionals and the scientific community, along with improving our understanding of colours as therapeutic agents in psychiatric illnesses.

\section{Materials and Methods}

The two primary procedures for Colour Therapy are:

1) Direct exposure to colored light

2) Hydrochromotherapy

Hydrochromotherapy is the method that involves irradiation of water through Visible Range Electromagnetic Radiations to produce color absorbed charged water [10] [11] [12] [13]. Both of these methodologies were adopted for the study.

\subsection{Sample Preparation for Hydrochromotherapy}

The whole procedure for preparing chromotized water was as follows: Transparent glass bottles each with 1 litre capacity were wrapped with $453.5 \mathrm{~nm}$ (Blue) filter sheets (Purity: 52\%; Transmission: 52\%). $750 \mathrm{ml}$ of distilled water was filled in the bottles. On a piece of wood (non-conducting surface), these bottles were placed in sunlight for 6 hours to facilitate the preparation process. Methodology was adopted from [10] [13].

\subsection{Direct Exposure}

A glass sheet of $9 \times 12$ inches was painted with $453 \mathrm{~nm}$ blue glass paint. The students were advised to watch this glass sheet for $15-20$ min before going to 
bed daily [10].

\subsection{Patients and Study Design}

150 female students of age 18 - 24 from a Government college (w) Gulberg in Lahore, Pakistan were chosen for the study with the consent of their family, with study conducted from $1^{\text {st }}$ March, 2017 to $12^{\text {th }}$ April, 2017.

Study inclusion criteria: Symptoms of anxiety and depression were elicited using a survey in the college for self-reported anxiety. 210 potential students were identified as borderline, or non-case of anxiety. Out these 210 students, 150 were selected for the study using simple random sampling. The socio-demographic characteristics of these students are shown in Table 1. These students were suffering from border-line anxiety. Borderline-case anxiety is equivalent to which might benefit from counseling or specific psychological interventions, such as anxiety management.

The students suffered from anxiety symptoms, including insomnia, palpitations, cold hands and feet and feelings of panic. The patients were randomised into two groups in 1:1; $(\mathrm{n}=75)$ to the students with anxiety (Group A) or to the control (Group $B),(n=75)$. The simple randomisation was done using a generated list of random numbers by a computer software.

In this situation, these groups were treated with $453 \mathrm{~nm}$ visible range radiation (blue color). In this case the patients of Group (A) were advised to take 90 $\mathrm{ml}(3 \mathrm{oz}$.) of blue $(453 \mathrm{~nm})$ chromotized water thrice a day one hour after each meal for six weeks. Along with this they were advised to watch blue glass sheets for 15 to 20 minutes before sleeping and to continue this therapy for 6 weeks in order to get good benefits. This therapy was limited to blue color only because blue color has been proved to control the disturbance of mental activity [7] [10]. Six weeks follow up was observed.

The control group of students did not take any other form of treatment for their anxiety.

\section{Results}

After two weeks, 60 patients experienced improvement in their self-reported anxiety from full case to below borderline in Group A in contrast to 20 patients in Group B. More patients who received chromotherapy showed an improvement than those who did not. Difference in mean improvement after two weeks was 3.48 ( $80 \%$ v $23 \%)$.

After four weeks of treatment, 9 students of Group A experienced improvement

Table 1. Socio-demographic characteristics of patient sample $(n=150)$.

\begin{tabular}{ccc}
\hline Independent Variables & Group A $(\mathrm{n}=75)$ & Group B (n=75) \\
\hline $\begin{array}{c}\text { Average Household Income }(1=\text { below average } \\
2=\text { average, } 3=\text { above average })\end{array}$ & 1 & 1 \\
Health Status $(1=$ very good, $2=$ good, $3=$ fair, $4=$ poor $)$ & 3 & 3 \\
\hline
\end{tabular}


in self-reported anxiety as compared to 12 patients in Group B $(2.86 ; 60 \% \mathrm{v}$ $22 \%)$.

After six Weeks, no patients had improvement in their anxiety in Group A (6 of them remained the same) compared to 7 in Group B (0;0\% v 15.2\%).

At the end of 6 weeks, the relation between the therapy and the improvement in anxiety was examined using the $\chi^{2}$ statistic using the cumulated data. The relation between these variables was significant, $(1, \mathrm{n}=150)=11.24, p<0.01$. i.e. Chromotherapy confers a greater improvement in anxiety than does no care. Difference in mean improvement at the end of study (after 6 weeks) was 1.92; 95\% CI, $p<0.01$. No recurrence was found after six-week follow-up.

Daily sessions of chromotherapy improved self-reported anxiety in college students, relieving symptoms of insomnia, headache and palpitations, with $80 \%$ of them recovering in the first 2 weeks of treatment (Figure 1). The patients in the control group experienced late recovery as compared to those given chromotherapy. As the results show, the difference in the improvement of self-reported anxiety between the Chromotherapy and the control even in this limited sample size was clear and persistent (Table 2).

\section{Discussion}

The doctrine of Colour therapy explains that visible electromagnetic radiations are the generators of electrical impulses and magnetic currents or fields of energy that are prime activators of the biochemical and hormonal processes [4]. Chromotherapy is based on the effect of visible range electromagnetic radiations on human neurohormonal pathways, precisely on melatonin and serotonin pathways in brain [5] [14]. Previous researches have concluded that certain parts of brain are light sensitive and respond differently to different colors. The mechanism depends on the stimulation of deep brain structures namely hypothalamus, pituitary and pineal gland by transduction of electromagnetic field trough

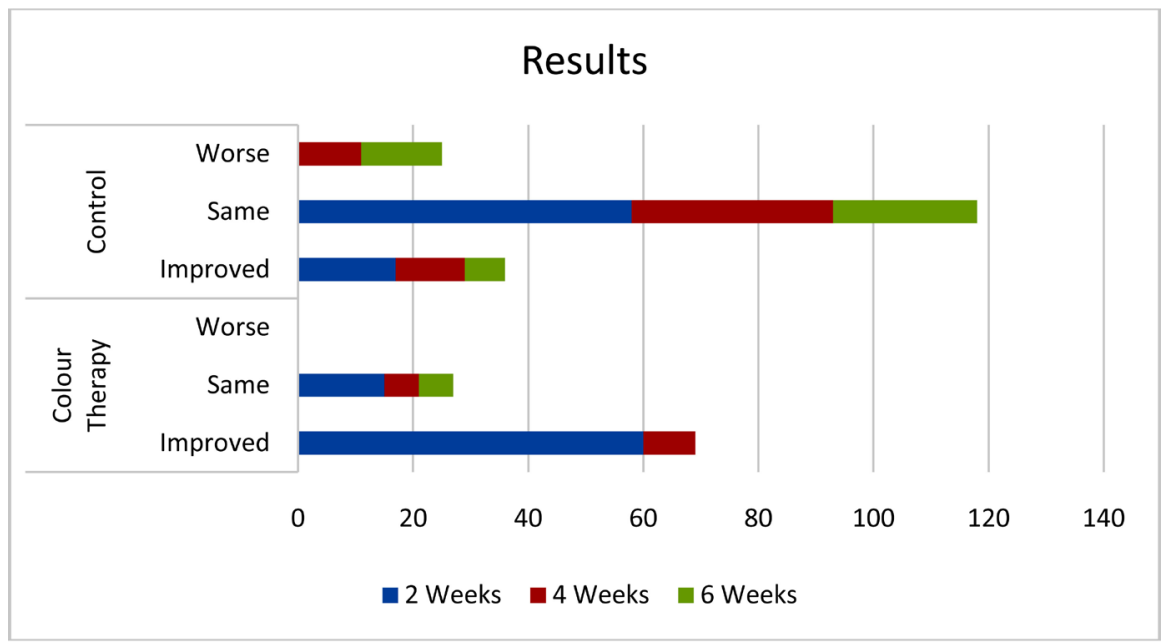

Figure 1. Shows the comparison between the recovery made by the Group A from anxiety as compared to Group B. The difference is significant with $80 \%$ of the students in Group. A recovering in the first 2 weeks as compared to $23 \%$ of Group B. 
Table 2. Effects of Colour Therapy on Self-reported anxiety.

\begin{tabular}{|c|c|c|c|}
\hline & $\begin{array}{c}\text { Total } \\
(\mathrm{n}=150)\end{array}$ & $\begin{array}{l}\text { Randomized to Colour Therapy } \\
\qquad(\mathrm{n}=75)\end{array}$ & $\begin{array}{l}\text { Randomized to Control } \\
\qquad(\mathrm{n}=75)\end{array}$ \\
\hline \multicolumn{4}{|c|}{$\chi^{2}$ statistic: $p<0.01$} \\
\hline \multicolumn{4}{|l|}{ Anxiety only } \\
\hline \multicolumn{4}{|c|}{ Outcome at 2 weeks, $\%$} \\
\hline Worse & 0 & 0 & 0 \\
\hline Same & 70 & 20 & 77 \\
\hline Improved & 80 & 80 & 23 \\
\hline \multicolumn{4}{|c|}{ Outcome at 4 weeks, \% } \\
\hline Worse & 7 & 0 & 19 \\
\hline Same & 33 & 40 & 60 \\
\hline Improved & 30 & 60 & 21 \\
\hline \multicolumn{4}{|c|}{ Outcome at 6 weeks, \% } \\
\hline Worse & 7 & 0 & 30 \\
\hline Same & 15 & 100 & 54 \\
\hline Improved & 18 & 0 & 15 \\
\hline
\end{tabular}

the visual pathway via retino-hypothalamic tract [14].

Several researches have demonstrated the profound effect of colors on human psychological processes such as behavior and mood [15] e.g. pink color has been shown to have a calming effect on the behavior of prisoners in the American penal system as it suppresses violent and aggressive behavior among inmates [16]. Chromotherapy is an effective, cost-effective and a safe alternative of treating anxiety (with no side-effects); It was thus adopted for this study.

Color therapy is the rationale therapy and has emerged with a serious scientific background for maintaining health and overcoming disease [6]. Different enzymes in each organ respond to particular wavelength in the visible region [17]. Each color influences us in different aspects. By learning how each color affects us, we can effectively use color to exceed energy blockage [10].

\section{Conclusion}

$453 \mathrm{~nm}$ (blue color) has proved to be an effective intervention for anxiety in students. It confers a greater improvement in anxiety than does no treatment (control).

\section{References}

[1] Hunt, J. and Eisenberg, D. (2010) Mental Health Problems and Help-Seeking Behavior among College Students. Journal of Adolescent Health, 46, 3-10. https://doi.org/10.1016/j.jadohealth.2009.08.008

[2] Offer, D. and Spiro, R.P. (1987) The Disturbed Adolescent Goes to College. Journal of American College Health, 35, 209-214. 
https://doi.org/10.1080/07448481.1987.9940443

[3] Stallman, H.M. (2010) Psychological Distress in University Students: A Comparison with General Population Data. Australian Psychologist, 45, 249-257. https://doi.org/10.1080/00050067.2010.482109

[4] Azeemi, S.T. and Raza, S.M. (2005) A Critical Analysis of Chromotherapy and Its Scientific Evolution. Evidence-Based Complementary and Alternative Medicine, 2, 481-488. https://doi.org/10.1093/ecam/neh137

[5] Radeljak, S., Žarković-Palijan, T., Kovačević, D. and Kovač, M. (2008) Chromotherapy in the Regulation of Neurohormonal Balance in Human Brain-Complementary Application in Modern Psychiatric Treatment. Collegium Antropologicum, 32, 185-188.

[6] Benchea, A., Babusca, D. and Morariu, M. (2015) Color in Alternative Therapy.

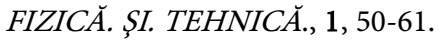

[7] Yousuf, R., Azeemi, S.T.Y. and Rashid, A. (2013) Treatment of Insomnia by Turquoise Colour (495 nm) during Pregnancy. Pakistan Postgraduate Medical Journal, 24, 67-69.

[8] Edelhäuser, F., Hak, F., Kleinrath, U., Lühr, B., Matthiessen, P.F., Weinzirl, J. and Cysarz, D. (2013) Impact of Colored Light on Cardiorespiratory Coordination. Evidence-Based Complementary and Alternative Medicine, 2013, Article ID 810876. https://doi.org/10.1155/2013/810876

[9] Azeemi, S.T., Mohsin Raza, S. and Yasinzai, M. (2011) A Case History of Treatment of Cutaneous Leishmaniasis by Visible Range Radiation Therapy. Chinese Medicine, 2,4 .

[10] Azeemi, K.S. (1999) Colour Therapy. Al-Kitab Publications, Karachi.

[11] Klotsche, C. (1993) Colour Medicine. Light Technology Publishing, Arizona.

[12] Azeemi, S.T., S. Mohsin Raza, M.Y. and Mujeeb-ur-Rehman (2008) Absorption of Radiant Energy in Water-A New Conjecture and Theory of Charge Quantization in Chromotized Water Samples. Science International, $20,7$.

[13] Azeemi, S.T.Y., Raza, S.M. and Ahmed, M.A. (2008) Newly Developed Recursive Relationship for Fractional Quantum States and Associated Energy Eigenvalues. Science International, 20, 255-260.

[14] Birren, F. (2016) Color Psychology and Color Therapy; A Factual Study of the Influence of Color on Human Life. Pickle Partners Publishing, Chicago, IL.

[15] Elliot, A.J. and Maier, M.A. (2014) Color Psychology: Effects of Perceiving Color on Psychological Functioning in Humans. Annual Review of Psychology, 65, 95-120. https://doi.org/10.1146/annurev-psych-010213-115035

[16] Schauss, A.G. (1979) Tranquilizing Effect of Color Reduces Aggressive Behavior and Potential Violence. Journal of Orthomolecular Psychiatry, 8, 218-221.

[17] Azeemi, S.T., Raza, S.M. and Yasinzai, M. (2008) Colors as Catalysts in Enzymatic Reactions. Journal of Acupuncture and Meridian Studies, 1, 139-142. https://doi.org/10.1016/S2005-2901(09)60034-0 